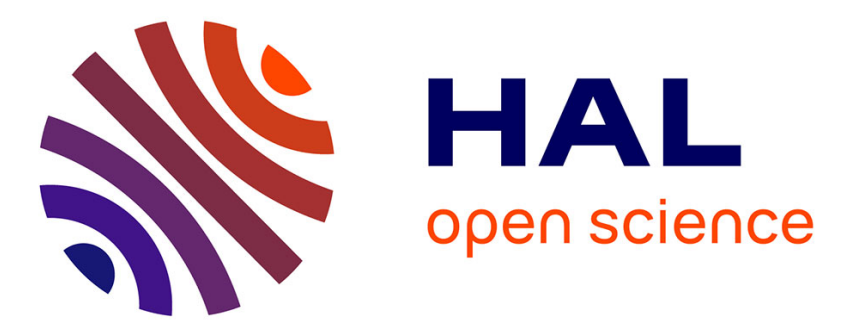

\title{
Normalized grip strength is a sensitive outcome measure through all stages of Duchenne muscular dystrophy
} Jean-Yves Hogrel, Valérie Decostre, Isabelle Ledoux, Marie de Antonio, Erik H Niks, Imelda de Groot, Volker Straub, Francesco Muntoni, Valeria Ricotti, Thomas Voit, et al.

\section{To cite this version:}

Jean-Yves Hogrel, Valérie Decostre, Isabelle Ledoux, Marie de Antonio, Erik H Niks, et al.. Normalized grip strength is a sensitive outcome measure through all stages of Duchenne muscular dystrophy. Journal of Neurology, 2020, 267 (7), pp.2022-2028. 10.1007/s00415-020-09800-9 . hal-02986642

\section{HAL Id: hal-02986642 \\ https://hal.sorbonne-universite.fr/hal-02986642}

Submitted on 3 Nov 2020

HAL is a multi-disciplinary open access archive for the deposit and dissemination of scientific research documents, whether they are published or not. The documents may come from teaching and research institutions in France or abroad, or from public or private research centers.
L'archive ouverte pluridisciplinaire HAL, est destinée au dépôt et à la diffusion de documents scientifiques de niveau recherche, publiés ou non, émanant des établissements d'enseignement et de recherche français ou étrangers, des laboratoires publics ou privés. 
Normalized grip strength is a sensitive outcome measure through all stages of Duchenne Muscular Dystrophy

Jean-Yves Hogrel ${ }^{1}, \mathrm{PhD}$, Valérie Decostre ${ }^{1}, \mathrm{PhD}$, Isabelle Ledoux ${ }^{1}, \mathrm{MSc}$, Marie de Antonio ${ }^{1}, \mathrm{MSc}, \mathrm{Erik}$ H. Niks², MD, Imelda de Groot ${ }^{3}$, MD, Volker Straub4, MD, Francesco Muntoni5,6, MD, PhD, Valeria Ricotti $^{6}$, MD, Thomas Voit ${ }^{5,6}, \mathrm{MD}, \mathrm{PhD}$, Andreea Seferian${ }^{1}, \mathrm{MD}$, Teresa Gidaro ${ }^{1}, \mathrm{MD}, \mathrm{PhD}$, Laurent Servais $^{7,8}, \mathrm{MD}, \mathrm{PhD}$

${ }^{1}$ Institute of Myology, GH Pitié-Salpêtrière, Paris, France

${ }^{2}$ Department of Neurology, Leiden University Medical Center, The Netherlands

${ }^{3}$ Radboud University Medical Center, Donders Center for Medical Neuroscience, Dept of

Rehabilitation, Nijmegen, The Netherlands

${ }^{4}$ The John Walton Muscular Dystrophy Research Centre, Newcastle Upon Tyne, UK

${ }^{5}$ Dubowitz Neuromuscular Centre, Great Ormond Street Institute of Child Health, University College London, UK

${ }^{6}$ NIHR Great Ormond Street Hospital Biomedical Research Centre, University College London, UK ${ }^{7} \mathrm{CHU}$ de Liège, Centre de Référence des Maladies Neuromusculaires, Liège, Belgium ${ }^{8}$ MDUK Neuromuscular Center, Department of Paediatrics, University of Oxford, Oxford, UK

Corresponding author: Jean-Yves Hogrel Institut de Myologie

GH Pitié-Salpêtrière

75651 PARIS Cedex 13

France

email: jy.hogrel@institut-myologie.org

phone: +33142165880

fax: +33 142165881 
ORCID identifiers

Jean-Yves Hogrel: 0000-0003-0045-7505

Marie de Antonio:_0000-0001-5114-0546

Erik H. Niks: 0000-0001-5892-5143

Imelda de Groot:0000-0003-1634-1427

Volker Straub: 0000-0001-9046-3540

Francesco Muntoni: 0000-0002-9102-5232

Valeria Ricotti: 0000-0003-1800-1987

Thomas Voit:_0000-0002-7424-5401

Teresa Gidaro: 0000-0002-9060-796X

Laurent Servais:_0000-0001-9270-4061

Running heading: Grip strength in Duchenne muscular dystrophy

Number of characters in title: 105

Number of characters in running head: 44

Number of words in abstract: 259

Number of words in main text: 2336

Number of figures: 2

Number of tables: 2

Keywords Duchenne muscular dystrophy; grip strength; outcome measures 


\section{ABSTRACT}

Objective The main aim was to explore the changes in hand-grip strength in patients with Duchenne muscular dystrophy (DMD) aged from 5 to 29 years. Secondary aims were to test the effect of mutation, ambulatory status and glucocorticoid use on grip strength and its changes over time and to compute the number of subjects needed for a clinical trial to stabilize grip strength.

Methods The analysis was performed on data collected during five international natural history studies on a cohort of DMD patients. Two hundred and two patients with genetically proven DMD were pooled from five different natural history studies. Excepting 13 patients with only one visit, the mean duration of follow-up was $2.2 \pm 1.6$ years. A total of 977 measurement points were collected. Grip strength was measured on the dominant side with a high precision dynamometer. The analysis was performed using absolute values and normalized values expressed in percentage of predicted values for age.

Results For absolute values, grip strength typically increased in ambulatory boys and decreased in non-ambulatory patients. However, when normalized, grip strength was already reduced at age 5 years and thereafter continued to fall away from normal values. The weaker the patients, the less strength they are prone to lose over again.

Interpretation Grip strength constitutes a sensitive and continuous outcome measure that can be used across all stages of DMD. Its measurement is easy to standardized, can be used in ambulatory and non-ambulatory patients and does not present any floor or ceiling effect. It is thus attractive as an outcome measure in therapeutic trials. 


\section{Introduction}

Duchenne Muscular Dystrophy (DMD) is a degenerative genetic muscle disease in which mutations in the dystrophin gene lead to muscle fiber degeneration and gradual replacement of muscle by fat and connective tissue. The clinical onset of symptoms usually appears in the lower limbs of boys before 4 years of age. DMD weakness typically affects proximal muscles first, with loss of distal muscle strength and function later. Muscles of the hands are thus affected later in the disease course, however also become progressively weakened and eventually paralyzed in the second and third decades of life. Despite the importance in maintaining strength and independent function as long as possible for young men with DMD[25], only few recent studies have focused on the upper limbs of DMD patients [6, 14, 17-19]. Hand and arm function is indeed associated with many domains of daily life activities (physical performance such as holding a glass, writing, turning a door knob, but also psychological and social functioning), so a key element in improving these may be to preserve arm function $[9,12]$.

Grip strength can be impaired from a young age in DMD, even long before the loss of ambulation [19, $25]$. It is correlated with the degree of physical disability [13, 21], is sensitive to change in the nonambulatory DMD population [21] and presents excellent reliability [22]. Maximal grip strength (MGS) measured with an appropriate handgrip dynamometer is a continuous variable that does not present any floor or ceiling effects in DMD [22]. However, these results have been observed on a rather limited number of patients and on a limited age range. Furthermore, reporting MGS as an absolute value rather than as a percentage of predicted values induces a confounding interference with physiological growth [6]. Indeed stature has been shown to be the main predictor of muscle strength during normal childhood development [5], with a smaller stature yielding lower strength. As height influences stride length, hence the distance walked within 6 minutes. We hypothesized that expressing MGS in percentage of predicted values rather than in absolute values could increase sensitivity to change by reducing the confounding factors of growth and maturation. 
The main aim of this study was to explore the progression of maximal grip strength during the course of DMD over a large range of age. Secondary aims were to test the effect of ambulatory status, glucocorticoid use and mutation on MGS and to compute the number of subjects needed for a clinical trial aiming to stabilize grip strength.

\section{Methods}

\section{Study design}

The results of MGS were gathered from five Ethical Review Board-approved natural history studies in DMD conducted between 2010 and 2019 (Table 1) in Paris (Institute of Myology), London (NIHR Great Ormond Street Biomedical Research Center), Newcastle (John Walton Muscular Dystrophy Research Center), Nijmegen (Radboud University Medical Center) and Leiden (Leiden University Medical Center). Molecular diagnosis of DMD was the only common inclusion criteria to all protocols. All patients or legal guardians for patients younger than 18 years of age gave written informed consent prior to participation in the studies.

\section{Measurement procedure}

MGS was measured using the MyoGrip device [22] (Figure 1) every 6 or 12 months depending on the study protocol. The Myogrip dynamometer is an electronic device specifically developed for measuring isometric grip strength in very weak patients, but which can also be used in healthy subjects. It measures forces in kilograms $(\mathrm{kg})$ from 0 to $90 \mathrm{~kg}$ with a resolution of $0.01 \mathrm{~kg}$ and an accuracy of $50 \mathrm{~g}$ over the whole range of measurement. Handle size is adjustable in a continuous way in order to fit at best the hand size of the subjects.

The physiotherapists of all centers were trained to use the same standardized operating procedure. All tests were performed with patients seated on a chair or in their wheelchair facing a table with the forearm placed on the table or on the wheelchair shelf. Before each test, patients were given a description of the grip task, a demonstration of the movement required and advice on maintaining correct practice. If standard upper limb position described by the protocol could not be maintained 
because of patient contractures, alternative positions were allowed. Trials were carried out with strong verbal encouragement asking the patients to provide maximal voluntary isometric contractions for 3 seconds. A rest period of about 30 seconds was respected between the trials. The trials were considered valid or not by the physiotherapist relying on several factors (compensations, motivation, understanding, positioning...). If the difference between two measurements was lower than $10 \%$ of the highest, the highest was accepted. If not, a subsequent measurement was made until two trials were within $10 \%$ with a maximum of 5 trials. The maximal value of all valid trials was kept for further analyses.

In two of the protocols (ULENAP and pre-Acti), two visits were performed within 14 days in order to assess the test-retest reliability of grip measurements.

\section{Statistical analysis}

MGS on the dominant side (defined as the writing/drawing hand) was analyzed using both absolute values (in $\mathrm{kg}$ ) and normalized values (in \% of predicted values for age). Equations of predictive models using chronological age were computed from previous data collected in healthy controls [4, $11,22]$ as following: before the age of 17 years: $M G S=3.40 \operatorname{EXP}(0.1527 \times$ age $)$ and after the age of 17 years: MGS $=45.66$ EXP(-0.001 $\times$ age $).$ Patients were classified according to their genotype, ambulatory status at the time of inclusion and glucocorticoid status. Test-retest reliability was assessed using an intraclass correlation coefficient (ICC) and a BlandAltman representation.

Linear mixed effects models were used to assess trends in grip changes over time. Interactions were included separately in the model as fixed effects between time and ambulatory status, glucocorticoids use or mutations. Models were adjusted for age at inclusion. Sample size was calculated by simulation study in order to determine the number of subjects required for a placebo-controlled clinical trial in which stabilization of the MGS in the treated group over one year should be detected, with an alpha risk of $5 \%$, and a power of $80 \%$. Grip values were simulated using linear mixed model included age, time, group and the interaction between age and 
group. We assumed no differences of grip value at baseline, so the coefficient value for the group where equal to 0 . Beta parameters were simulated from a Gaussian distribution using results provided by the linear mixed model. When grip strength was expressed in $\mathrm{kg}$, the stabilization meant that the grip evolution over time of treated patient was equal to the grip evolution of healthy controls. When grip strength was expressed in \% predicted values, the stabilization meant that the change was $0 \%$. We assumed than the variability of the treated group was the same than the DMD population presented in this study.

Analyses were performed using R 3.3.1 software (R Foundation for Statistical Computing, Vienna, Austria). Statistical significance was set at 0.05 .

\section{Results}

\section{Population description}

A total of 202 subjects (5.0-28.7 years) were included in this cohort study (see Table 1). At baseline, 92 patients were ambulatory and 110 were non-ambulatory. With the exception of 13 subjects who had only one visit, the mean follow-up duration was $2.2 \pm 1.6$ years (range: $0.04-6.53$ years). A total of 977 measurement points was collected. Eighty-six ambulatory patients (93\%) were treated with glucocorticoids, whilst only 53 non-ambulatory patients (48\%) were. Fifty-nine patients had mutations amenable to exon skipping for exon 53,28 for exon $44 ; 15$ for exon 45,25 for exon 51,74 patients had other deletions ( 4 mutations amenable to exon skipping for exon 8,3 for exon 43,8 for exon 50, 3 for exon 52, 8 for exon 55 and 23 others) or other mutations ( 7 duplication, 2 insertion, 4 missense, 12 nonsense mutations), and 1 had an unknown mutation.

\section{Grip strength measurement reliability}

Test-retest reliability was assessed on 104 independent measurements (Figure 2). The intraclass correlation coefficient was 0.977 . 


\section{Grip strength change during the life of DMD patients}

Absolute values of MGS increased by $0.23 \mathrm{~kg} /$ year on average in ambulatory boys and decreased by $0.34 \mathrm{~kg} /$ year in non-ambulatory patients (Figure 3.A). When expressed as percentage of predicted values for age, MGS decreased in both groups (Figure 3.B). This decrease was significantly more important in ambulatory patients compared to non-ambulatory patients (-4.95 \% points per year vs. $2.53 \%$ points per year; $p<0.001)$.

\section{Effect of DMD mutation, corticosteroid treatment and ambulatory status on grip strength}

Glucocorticoids had a positive effect on muscle strength since the subjects without glucocorticoids were $6.3 \%$ weaker than patients treated with glucocorticoids $(p<0.001)$. However patients treated with glucocorticoids lost significantly more strength (significant difference of $-2.84 \%$ points per year, $p<0.001)$.

Patients amenable to exon skipping 45, 51 and 53 were significantly weaker than patients amenable to exon skipping 44 (significant difference of $13.7 \%, 9.3 \%$ and $13.9 \%$, respectively, $p<0.05$ ). However the latter group lost significantly more strength per year (-5.8\% points per year) than patients amenable to exon skipping 45 and 53 (significant difference of $3.0 \%$ points per year and $2.7 \%$ point per year, respectively).

\section{Computation of the patient number needed for stabilizing grip strength during a therapeutic trial}

Following the methodology specified in the Methods section, the number of patients per arm needed for a clinical trial is presented in Table 2 .

\section{Discussion}

We showed that maximal grip strength expressed in percentage of predicted value counterbalances the cofounding effect of growth during childhood and can be used as continuous variable to measure the functional decline due to Duchenne muscular dystrophy across all stages of the disease. The 
analyses demonstrated the decrease of grip strength in a large population of DMD patients aged from 5 to 30 years compared to normal values. It is often suggested that upper limb function begins to deteriorate in DMD around the age of $9-12$ years when assessed using scales $[7,8,18]$. This statement is partly due to the ceiling effect of scales. The use of high precision dynamometry and normalized values clearly demonstrates that grip strength decline can be captured at a younger age, as early as 5 years of age, as already underlined in the CINRG longitudinal study cohort [1] or other studies $[19,25]$. The changes in grip strength described in the present study are perfectly in line with those recently published on a part of the cohort by Ricotti et al [20]. However, the clinical meaningfulness of these changes has yet to be established; for example, upper limb functional limitations are most likely not clinically significant at 5 years of age, since DMD boys have sufficient strength for daily tasks, as well as full range of motion and ability to compensate for their strength deficit. In the context of a clinical trial, the relatively well-preserved muscles could offer the opportunity to study the effect of disease modifying drugs by way of measuring a stabilization (or even an improvement) in strength in response to therapies, where scales may suffer from a ceiling or a floor effect.

The age-dependence of MGS changes suggests that its decline was inversely proportional to age. The weaker the patients, the less strength they are prone to lose over again. Similar exponential-like decrease have already been observed for other variables. For example, forced vital capacity, which is a variable generally expressed in percentage of predicted values, was also described as exponentially decreasing in DMD patients of equivalent ages $[2,10]$. Outcome measures are generally presented in absolute values. The six-minute walk test (6MWT) has been the most widely used primary endpoint in therapeutic trials. The distance (in $\mathrm{m}$ ) of the 6MWT is generally described as improving up to age of 7 due to maturation effect, before reaching a plateau and then declining [15]. This inversed Ushaped curve was also observed in MGS absolute values, where patients improved up to roughly 12 years and then decreased afterwards. A powerful way of minimizing the cofounding factors of 
growth and maturation is to express performance in percentage of predicted values for the considered variables [16]. This is particularly critical in children as they are growing [5]. In this report, we chose to express the model only in terms of age, since it avoids a possible error of measurement in a multicenter setting, but more powerful predictive equations were obtained in controls using hand circumference. Further studies should include a consistent estimate of stature such as height, ulnar length or hand circumference, which has been shown to be a strong predictive determinant of MGS [4]. It can be easily assessed even in wheelchair-bound patients with contractures using strict measurement procedures.

Many factors influence muscle strength measurement and may act as confounding factors: genetics (mutation, genetic modifiers), developmental factors (chronological age, growth, pubertal status, stature), symptomatology (contractures, cognitive status), neural factors (compensation abilities, motor strategy, neural plasticity), behavioral factors (psychological status, motivation, self-esteem), environmental factors (social and cultural background) and obviously standards of care and assessors. These factors may explain, at least partly, the large variability between DMD subjects. Indeed, grip strength can be very heterogeneous among patients (see for instance Figure 3 in Seferian et al [21] or Figures 3 and 4 in Connelly et al [2]). The decline in MGS appeared however sensitive enough to detect a difference between exon 44 and exon 53 skippable patients, two genotypes that are known to be slightly less and more severe, respectively [23, 24]. The European Medical Agency reported in their guidelines that "for total evidence of clinical efficacy an effect on motor function should be supported by an effect on muscle strength" [3]. Indeed the main function of a muscle is to contract, to produce a mechanical force, to make the movement possible and translate it into an action. This function is primarily impaired in neuromuscular disorders. The assessment of strength is thus a direct measure of the muscle capacity and is a key feature to follow during the natural course of the disease but more importantly during the possible recovery of the muscle capacity to generate force. Due to the fact that the data were gathered from 
several protocols, there was unfortunately no common functional scale to use before MGS, which is a limitation of the present work.

The constant relative decline of MGS in both ambulatory and non-ambulatory DMD subjects, the absence of floor and ceiling effects, the good reliability of the measurements, the possibility to standardize data acquisition and finally the direct link between muscle function and strength production [21] makes maximal grip strength an attractive outcome measure for DMD trials. Further work is needed to quantify minimally clinically meaningful change using functional scales and demonstrate positive changes during interventional studies.

\section{Acknowledgements:}

Grip strength data in Duchenne muscular dystrophy (DMD) using the MyoGrip device were gathered through several natural history studies in several sites (London, Newcastle, Leiden, Nijmegen and Paris). The ULENAP study was sponsored by the Institute of Myology and funded by the Association Française contre les Myopathies. The pre-U7 study was sponsored by Genethon. This project was supported by the AFM (Association Française contre les Myopathies) and by ADNA (Advanced Diagnostics for New Therapeutic Approaches), a program dedicated to personalized medicine, coordinated by the Institut Mérieux and supported by research and innovation aid from the French public agency, OSEO. The pre-Acti study was sponsored by the Institute of Myology and funded by the Association Française contre les Myopathies. The iMDEX natural history study was sponsored by each participating center and funded by the Association Française contre les Myopathies. The SRP4053 study was sponsored by Sarepta. No funders were involved in data collection, analyses or interpretation or in the preparation of this paper. They all gave their agreement for the use of data. In particular the authors wish to personally thank Geneviève Laforet and Elisabeth Thomson (from Sarepta) and Géraldine Honnet (from Généthon). This research was also supported by the NIHR Great Ormond Street Hospital Biomedical Research Centre. 
We thank the patients and their families for their participation in the studies used in the present meta-analysis. The grip strength data have been acquired in different protocols by several physiotherapists. We acknowledge the dedicated work of Gwenn Ollivier, Aurélie Canal, Charlotte Lilien and Stéphanie Gilabert (Paris), Merel Jansen, Maaike Pelsma and Anke Langelaan (Nijmegen), Menno van der Holst (Leiden), Vic Selby and Jordan Butler (London), Michela Guglieri, Alexander Murphy and Anna Mayhew (Newcastle). We are also grateful to Amélie Moraux and Pauline Hivert for the management of the MyoGrip database and to Simone Birnbaum for thorough proofreading of the manuscript and text improvement.

The authors would like to pay tribute to the memory of Joana Pisco Domingos, suddenly deceased in early January 2018.

\section{Author contributions:}

Designing the studies: J-Y.H., V.S., F.M., T.V., L.S.

Methodology of grip strength measurements: J-Y. H., V.D.

Acquisition of the data: E.N., I.G., V.S., F.M., V.R., T.V., A.S., T.G., L.S.

Analysis of data: J-Y.H., I.L., M.D.A.

Data interpretation: J-Y.H., L.S.

Drafting the manuscript and the figures: J-Y.H.

Revising and approving the manuscript: all authors

Study supervision: J-Y.H., L.S.

\section{Potential conflicts of interest:}

Jean-Yves Hogrel is the inventor of the MyoGrip device (patented). Erik Niks reports consultancies for BioMarin, Summit and WAVE for which reimbursements were received by the LUMC. Imelda de Groot has received consulting and education fees from PTC Therapeutics, Santhera, Biomarin/Prosensa. Volker Straub received speaker honoraria from Sanofi Genzyme and has 
participated in advisory boards for Audentes Therapeutics, Biogen, Bristol-Myer Squibb, Exonics Therapeutics, Italfarmaco S.p.A., Pfizer, Roche, Sanofi Genzyme, Sarepta Therapeutics, Summit Therapeutics, UCB, and Wave Therapeutics. He has research collaborations with Ultragenyx and Sanofi Genzyme. Francesco Muntoni has received consulting fees from Biogen, Italfarmaco, Pfizer, PTC Therapeutics, Roche, Sarepta Therapeutics, and Wave Therapeutics; and is involved as Chief Investigator in the EUFP7 / Sarepta Therapeutics funded clinical trial (SKIP NMD study, EU FP 7 No. HEALTH-F4-2012-30537) and principal investigator in the Sarepta Therapeutics funded study ESSENCE. He is also supported by the National Institute of Health Research Biomedical Research Centre at Great Ormond Street Hospital for Children NHS Foundation Trust, and University College London. The support of the MRC Neuromuscular Centre Biobank and of the Muscular Dystrophy UK is also gratefully acknowledged. Thomas Voit serves on scientific advisory boards for Constant Pharmaceuticals and Metriopharm; he is a co-founder of AlterGene; he serves or served as a consultant for Biomarin, Biophytis, Evox, Capricor, Catabasis, Debiopharm, Italfarmaco, Santhera, Sarepta, Servier, Solid and Summit. Teresa Gidaro has served on scientific advisory boards for PTC and Ultragenyx. Laurent Servais has received consulting fees from Roche, Biogen, Avexis, Cytokinetics, Sarepta, Biomarin, Santhera, Servier, Biophytis and Dynacure. He is coordinating natural history studies funded by Valerion, Dynacure and Roche. The other authors report no disclosure.

\section{Ethical standards}

All studies have been approved by the appropriate ethics committee and have, therefore, been performed in accordance with the ethical standards laid down in the 1964 Declaration of Helsinki and its later amendments. All patients or legal guardians for patients younger than 18 years of age gave written informed consent prior to participation in the studies. 


\section{References}

1. Bushby K, Connor E (2011) Clinical outcome measures for trials in Duchenne muscular dystrophy: report from International Working Group meetings. Clin Investig (Lond) 1:12171235

2. Connolly AM, Malkus EC, Mendell JR, Flanigan KM, Miller JP, Schierbecker JR, Siener CA, Golumbek PT, Zaidman CM, McDonald CM, Johnson L, Nicorici A, Karachunski PI, Day JW, Kelecic JM, Lowes LP, Alfano LN, Darras BT, Kang PB, Quigley J, Pasternak AE, Florence JM, Network MDCR, Anand P, Wulf CO, Goude E, Dalton JC, Viollet-Callendret L, Buser KK, Shriber E, Parad R (2015) Outcome reliability in non-ambulatory boys/men with Duchenne muscular dystrophy. Muscle Nerve 51:522-532

3. EMA (2011) Guideline on the clinical investigation of medicinal products for the treatment of Duchenne and Becker muscular dystrophy.

4. Hogrel J-Y (2015) Grip strength measured by high precision dynamometry in healthy subjects from 5 to 80 years. BMC Musculoskelet Disord 16:139

5. Hogrel J-Y, Decostre V, Alberti C, Canal A, Ollivier G, Josserand E, Taouil I, Simon D (2012) Stature is an essential predictor of muscle strength in children. BMC Musculoskelet Disord $13: 176$

6. Hogrel J-Y, Wary C, Moraux A, Azzabou N, Decostre V, Ollivier G, Canal A, Lilien C, Ledoux I, Annoussamy M, Reguiba N, Gidaro T, Le Moing AG, Cardas R, Voit T, Carlier PG, Servais L (2016) Longitudinal functional and NMR assessment of upper limbs in Duchenne muscular dystrophy. Neurology 86:1022-1030

7. Janssen MMHP, Bergsma A, Geurts ACH, de Groot IJM (2014) Patterns of decline in upper limb function of boys and men with DMD: an international survey. J Neurol 261:1269-1288

8. Jung I-Y, Chae JH, Park SK, Kim JH, Kim JY, Kim SJ, Bang MS (2012) The correlation analysis of functional factors and age with duchenne muscular dystrophy. Ann Rehabil Med 36:22-32 
9. Klingels K, Mayhew AG, Mazzone ES, Duong T, Decostre V, Werlauff U, Vroom E, Mercuri E, Goemans NM, Upper Limb Clinical Outcome G, Eagle M, De Groot I, Main M, Messina S, Campion G, Servais L, Van den Hauwe M, Es E, Pane M, Buccella F, Kuijer J, Ceradini F, Henricson E, McDonald C, Florence J (2017) Development of a patient-reported outcome measure for upper limb function in Duchenne muscular dystrophy: DMD Upper Limb PROM. Dev Med Child Neurol 59:224-231

10. Kohler M, Clarenbach CF, Bahler C, Brack T, Russi EW, Bloch KE (2009) Disability and survival in Duchenne muscular dystrophy. J Neurol Neurosurg Psychiatry 80:320-325

11. Li K, Hewson DJ, Duchene J, Hogrel J-Y (2010) Predicting maximal grip strength using hand circumference. Man Ther 15:579-585

12. Lue Y-J, Chen S-S, Lu Y-M (2017) Quality of life of patients with Duchenne muscular dystrophy: from adolescence to young men. Disabil Rehabil 39:1408-1413

13. Mattar FL, Sobreira C (2008) Hand weakness in Duchenne muscular dystrophy and its relation to physical disability. Neuromuscul Disord 18:193-198

14. Mayhew A, Mazzone ES, Eagle M, Duong T, Ash M, Decostre V, Vandenhauwe M, Klingels K, Florence J, Main M, Bianco F, Henrikson E, Servais L, Campion G, Vroom E, Ricotti V, Goemans N, McDonald C, Mercuri E, Performance of the Upper Limb Working G (2013) Development of the Performance of the Upper Limb module for Duchenne muscular dystrophy. Dev Med Child Neurol 55:1038-1045

15. Mazzone ES, Pane M, Sormani MP, Scalise R, Berardinelli A, Messina S, Torrente Y, D'Amico A, Doglio L, Viggiano E, D'Ambrosio P, Cavallaro F, Frosini S, Bello L, Bonfiglio S, De Sanctis R, Rolle E, Bianco F, Magri F, Rossi F, Vasco G, Vita G, Motta MC, Donati MA, Sacchini M, Mongini T, Pini A, Battini R, Pegoraro E, Previtali S, Napolitano S, Bruno C, Politano L, Comi GP, Bertini E, Mercuri E (2013) 24 month longitudinal data in ambulant boys with Duchenne muscular dystrophy. PLoS One 8:e52512 
16. McDonald CM, Henricson EK, Abresch RT, Florence JM, Eagle M, Gappmaier E, Glanzman AM, Group PG-DS, Spiegel R, Barth J, Elfring G, Reha A, Peltz S, Ryan M, Jones K, Goemans N, Campbell C, Mah J, Selby K, Voit T, Chabrol B, Pereon Y, Schara U, Kirschner J, Bertini E, Mercuri E, Comi G, Nevo Y, Vilchez J, Colomer J, Children S, Tulinius M, Sejersen T, Bushby K, Muntoni F, Quinlivan RCM, Wong B, Finkel RS, Sampson JB, Flanigan KM, Butterfield R, Day JW, Mathews K, Darras BT, Apkon SD, Parsons J, Barohn R, Connolly A, lannaccone S, Sproule DM, Kaufman P, Han JJ, Joyce NC, Renfroe JB, Russman BS, Burns-Wechsler S, Moore SA, Sweeney HL, Coleman K (2013) The 6-minute walk test and other endpoints in Duchenne muscular dystrophy: longitudinal natural history observations over 48 weeks from a multicenter study. Muscle Nerve 48:343-356

17. Pane M, Coratti G, Brogna C, Mazzone ES, Mayhew A, Fanelli L, Messina S, D'Amico A, Catteruccia M, Scutifero M, Frosini S, Lanzillotta V, Colia G, Cavallaro F, Rolle E, De Sanctis R, Forcina N, Petillo R, Barp A, Gardani A, Pini A, Monaco G, D'Angelo MG, Zanin R, Vita GL, Bruno C, Mongini T, Ricci F, Pegoraro E, Bello L, Berardinelli A, Battini R, Sansone V, Albamonte E, Baranello G, Bertini E, Politano L, Sormani MP, Mercuri E (2018) Upper limb function in Duchenne muscular dystrophy: 24 month longitudinal data. PLoS One 13:e0199223

18. Pane M, Mazzone ES, Fanelli L, De Sanctis R, Bianco F, Sivo S, D'Amico A, Messina S, Battini R, Scutifero M, Petillo R, Frosini S, Scalise R, Vita G, Bruno C, Pedemonte M, Mongini T, Pegoraro E, Brustia F, Gardani A, Berardinelli A, Lanzillotta V, Viggiano E, Cavallaro F, Sframeli M, Bello L, Barp A, Bonfiglio S, Rolle E, Colia G, Catteruccia M, Palermo C, D'Angelo G, Pini A, lotti E, Gorni K, Baranello G, Morandi L, Bertini E, Politano L, Sormani M, Mercuri E (2014) Reliability of the Performance of Upper Limb assessment in Duchenne muscular dystrophy. Neuromuscul Disord 24:201-206 
19. Pizzato TM, Baptista CRJA, Souza MA, Benedicto MMB, Martinez EZ, Mattiello-Sverzut AC (2014) Longitudinal assessment of grip strength using bulb dynamometer in Duchenne Muscular Dystrophy. Braz J Phys Ther 18:245-251

20. Ricotti V, Selby V, Ridout D, Domingos J, Decostre V, Mayhew A, Eagle M, Butler J, Guglieri M, Van der Holst M, Jansen M, Verschuuren JJGM, de Groot IJM, Niks EH, Servais L, Straub V, Voit T, Hogrel JY, Muntoni F (2019) Respiratory and upper limb function as outcome measures in ambulant and non-ambulant subjects with Duchenne muscular dystrophy: A prospective multicentre study. Neuromuscul Disord 29:261-268

21. Seferian AM, Moraux A, Annoussamy M, Canal A, Decostre V, Diebate O, Le Moing A-G, Gidaro T, Deconinck N, Van Parys F, Vereecke W, Wittevrongel S, Mayer M, Maincent K, Desguerre I, Themar-Noel C, Cuisset J-M, Tiffreau V, Denis S, Jousten V, Quijano-Roy S, Voit T, Hogrel J-Y, Servais L (2015) Upper limb strength and function changes during a one-year follow-up in non-ambulant patients with Duchenne Muscular Dystrophy: an observational multicenter trial. PLoS One 10:e0113999

22. Servais L, Deconinck N, Moraux A, Benali M, Canal A, Van Parys F, Vereecke W, Wittevrongel S, Mayer M, Desguerre I, Maincent K, Themar-Noel C, Quijano-Roy S, Serari N, Voit T, Hogrel JY (2013) Innovative methods to assess upper limb strength and function in non-ambulant Duchenne patients. Neuromuscul Disord 23:139-148

23. Servais L, Montus M, Guiner CL, Ben Yaou R, Annoussamy M, Moraux A, Hogrel JY, Seferian AM, Zehrouni K, Le Moing AG, Gidaro T, Vanhulle C, Laugel V, Butoianu N, Cuisset JM, Sabouraud P, Cances C, Klein A, Leturcq F, Moullier P, Voit T (2015) Non-Ambulant Duchenne Patients Theoretically Treatable by Exon 53 Skipping have Severe Phenotype. J Neuromuscul Dis 2:269-279

24. van den Bergen JC, Ginjaar HB, Niks EH, Aartsma-Rus A, Verschuuren JJ (2014) Prolonged Ambulation in Duchenne Patients with a Mutation Amenable to Exon 44 Skipping. J Neuromuscul Dis 1:91-94 
25. Wagner MB, Vignos PJ, Jr., Carlozzi C, Hull AL (1993) Assessment of hand function in Duchenne muscular dystrophy. Arch Phys Med Rehabil 74:801-804 
Table 1. Main information of the natural history studies used in the present report.

\begin{tabular}{|c|c|c|c|c|c|c|}
\hline Study & NCT & Sponsor & $\begin{array}{l}\text { Age range at } \\
\text { inclusion }\end{array}$ & Mutations & Ambulatory status & $\mathbf{N}$ \\
\hline ULENAP & NCT00993161 & Institut de Myologie & {$[9.0 . .28 .1]$} & any & non-ambulatory & 51 \\
\hline pre-U7 & NCT01385917 & Généthon & {$[6.0 . .20 .6]$} & exon 53 skippable & both & 40 \\
\hline pre-Acti & NCT01611597 & Institut de Myologie & [10.7..28.7] & any & non-ambulatory & 7 \\
\hline iMDEX & NCT02780492 & each center & [4.9..18.1] & any & both & 90 \\
\hline SRP-4053 & NCT02310906 & Sarepta & {$[6.1 . .12 .2]$} & any & ambulatory & 14 \\
\hline pooled & & & {$[4.9 . .28 .7]$} & any & both & 202 \\
\hline
\end{tabular}

NCT: ClinicalTrials.gov Identifier 
Table 2. Number of subjects per arm needed for a clinical trial to stabilize grip strength expressed either in absolute or relative values.

\begin{tabular}{cccccc} 
& \multicolumn{2}{c}{ Ambulatory patients } & & \multicolumn{2}{c}{ Non-ambulatory patients } \\
\cline { 2 - 3 } \cline { 5 - 6 } & $\mathrm{kg}$ & \% point & & $\mathrm{kg}$ & \% point \\
\hline $\mathrm{n}$ & 45 & 62 & & 121 & 39 \\
\hline
\end{tabular}




\section{Figures captions}

Figure 1. The MyoGrip device.

Figure 2. Test-retest reliability assessed using ICC (A) and Bland-Altman plot (B).

Figure 3. Grip strength change with age either expressed in absolute values $(A)$ or in percentage of predicted value for age (B). 
Figure 1

A

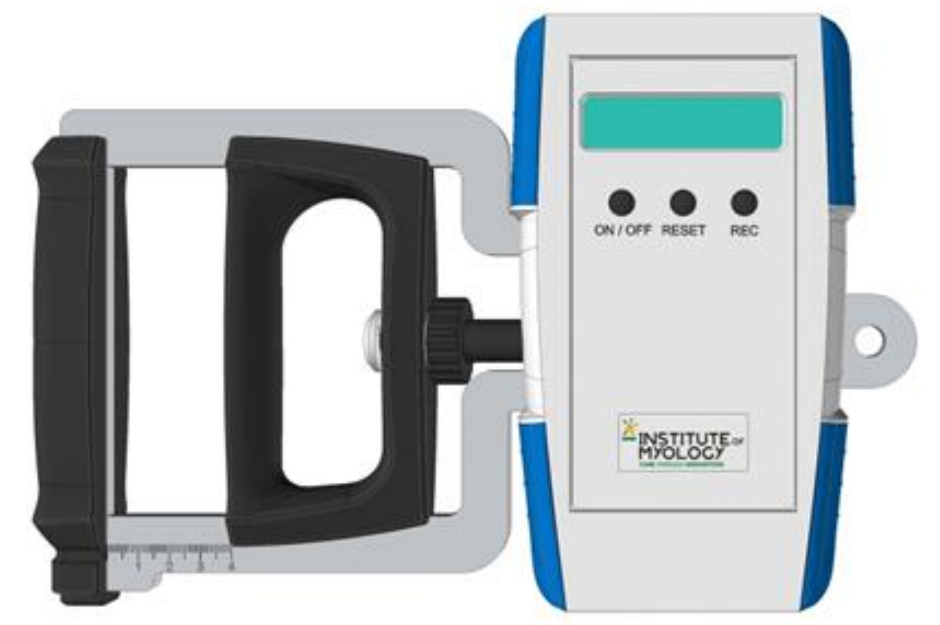

B

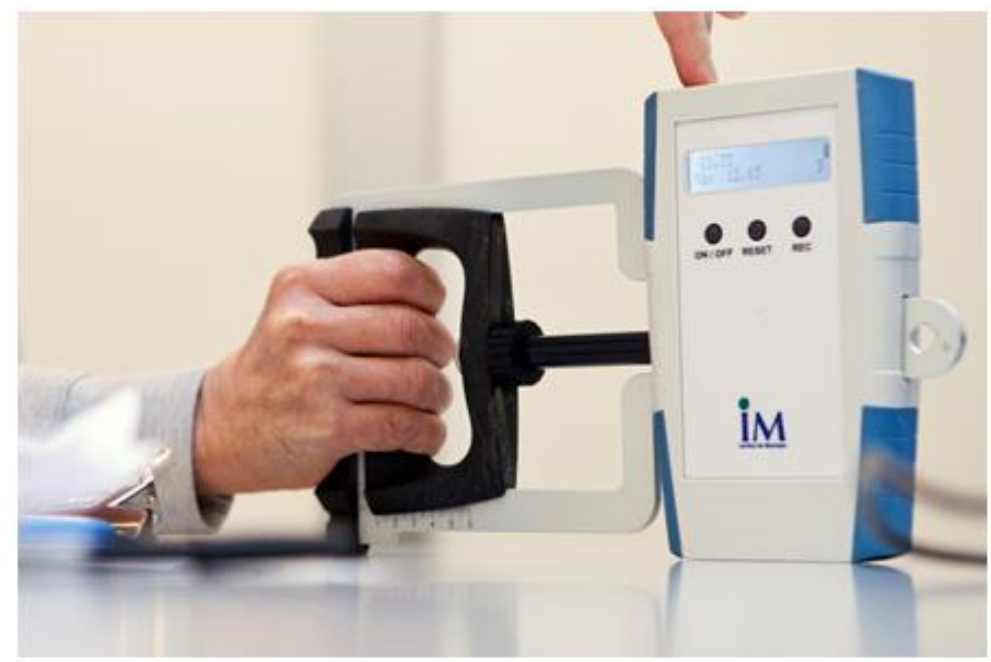


Figure 2
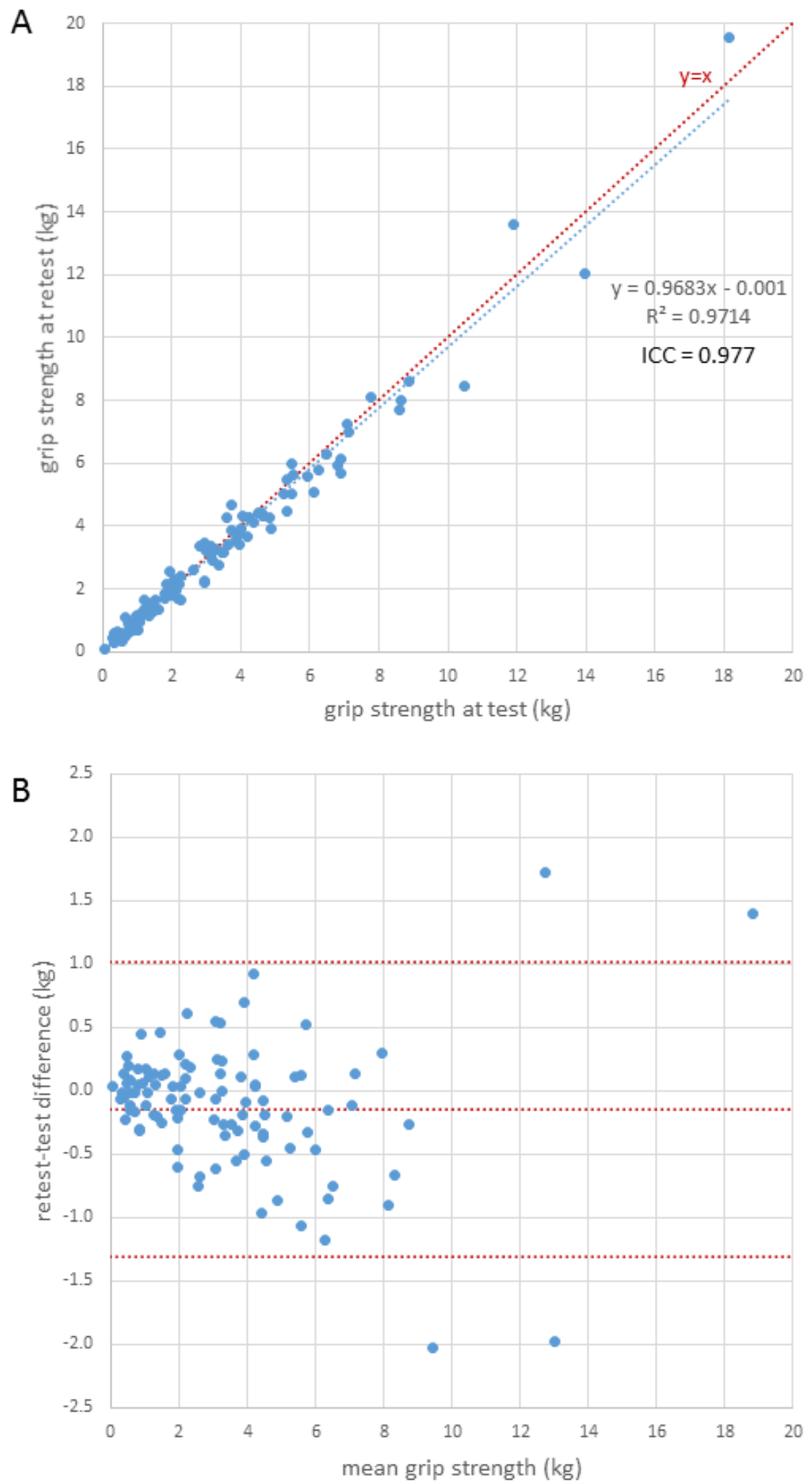
Figure 3
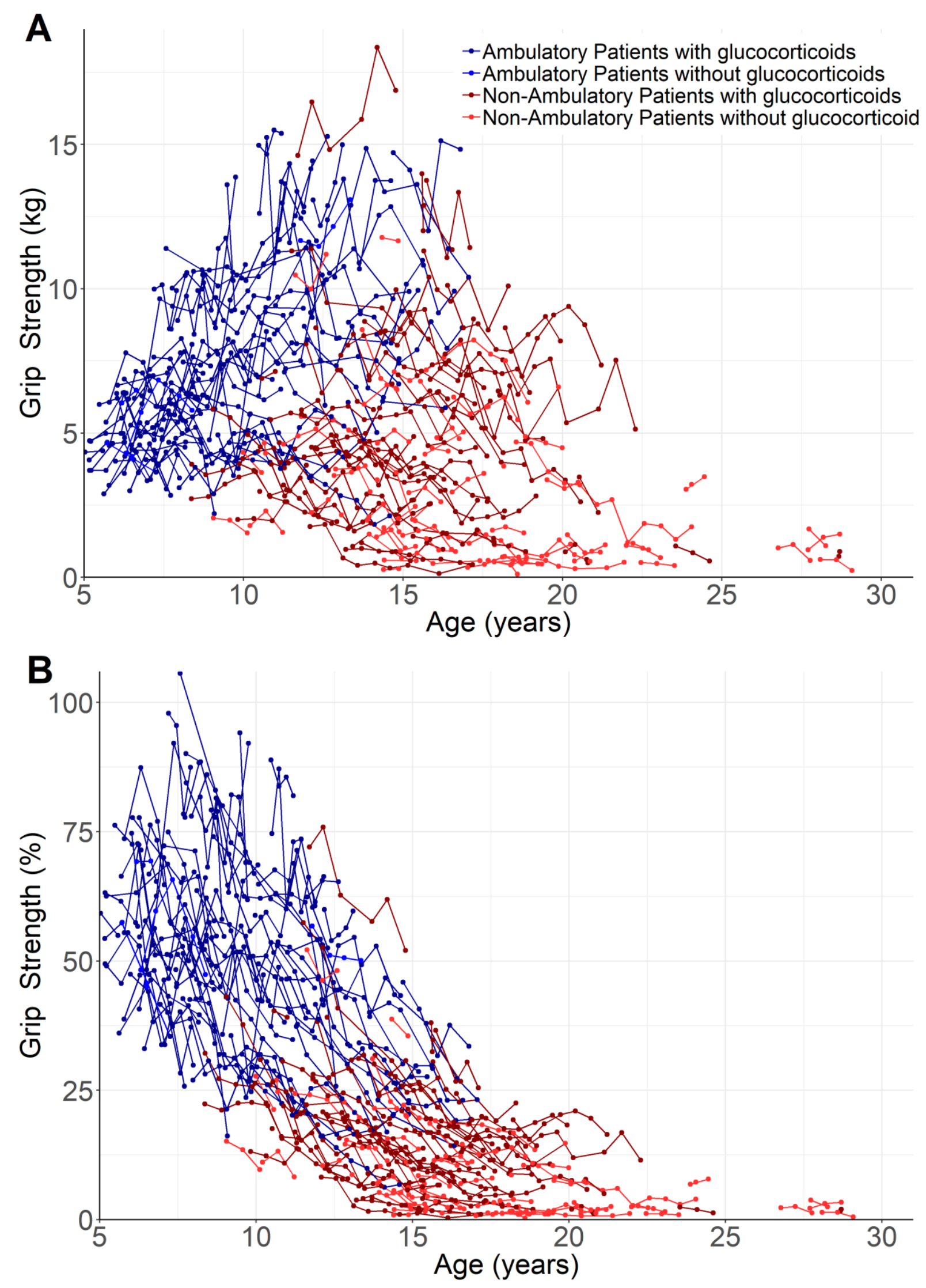